\title{
Editorial note for the special issue "Dynamics and physiological processes of tree roots"
}

\author{
Kyotaro Noguchi ${ }^{1} \cdot$ Takayoshi Koike $^{2}$
}

Published online: 21 March 2016

(C) Springer-Verlag Berlin Heidelberg 2016

Plant roots are well known to have key roles in water and nutrient acquisition from soils. Recent studies using molecular techniques have facilitated our understanding of these physiological processes in tree roots (Mclean et al. 2011; Alber et al. 2012; Laur and Hacke 2013). On the other hand, a number of studies in the past decades have focused on tree roots as essential in carbon dynamics in terrestrial ecosystems, in which fine roots are a key component of below-ground carbon flux, whereas coarse roots function as a carbon reservoir (Brunner and Godbold 2007). In addition, recent studies have started to examine the effects of biodiversity on root dynamics or interactions between roots and other organisms, which are important topics to deepen our comprehensive understanding about ecosystem functions of tree roots (Brassard et al. 2013; Meier et al. 2013). Although studying roots that are hidden in the soil is often difficult, new techniques such as non-destructive imaging have been applied to better understand the dynamics of tree roots (Nakaji et al. 2008; Hirano et al. 2012).

In September 2014, the "Sixth international symposium on physiological processes in roots of woody plants" was held at Nagoya University, Japan. In this symposium, current woody root studies were reported by 37 oral and 77 poster presentations. The topics discussed in the symposium were quite diverse including root growth dynamics, water

Kyotaro Noguchi

kyotaro@affrc.go.jp

Takayoshi Koike

tkoike@for.agr.hokudai.ac.jp

1 Forestry and Forest Products Research Institute, Tsukuba 305-8687, Japan

2 Silviculture and Forest Ecological Studies, Hokkaido University, Sapporo 060-8589, Japan and nutrient uptake, below-ground carbon allocation and biological interactions (e.g. symbiosis, biodiversity effects). This special issue "Dynamics and physiological processes of tree roots" was provided by 21 excellent papers, most of which were from the symposium in Nagoya.

In the first part of this special issue, $\mathrm{CO}_{2}$ flux in roots and effects of elevated atmospheric $\mathrm{CO}_{2}$ on root dynamics were highlighted. Although a number of papers were published on root dynamics related to below-ground carbon flux in the past decades as mentioned above, there are still many uncertainties. Bloemen et al. (2016), in their review, showed that a substantial proportion of $\mathrm{CO}_{2}$ derived from root respiration remained in root systems and was transported through the transpiration stream. Although these findings were obtained from a limited number of species so far, this phenomenon could impact our current understanding of carbon dynamics in terrestrial ecosystems or $\mathrm{CO}_{2}$ metabolism in trees. Agathokleous et al. (2016) and Wang et al. (2016) reported results obtained by free-air- $\mathrm{CO}_{2}$ enrichment (FACE) experiments using deciduous broadleaved species (Betula and Quercus species) in Hokkaido, northern Japan. They examined the effects of elevated $\mathrm{CO}_{2}$ on the trees grown on two different types of the soil [fertile brown forest soil (BF) and immature volcanic ash soil (VA)]. Agathokleous et al. (2016) showed that elevated $\mathrm{CO}_{2}$ increased the growth of whole roots in nutrient poor VA soil, but not in fertile BF soil. Wang et al. (2016), on the other hand, reported that elevated $\mathrm{CO}_{2}$ decreased standing crop of fine roots and increased their life spans especially in the VA soil. The responses of tree roots to elevated $\mathrm{CO}_{2}$ varied with factors such as soil resource availability and periods of $\mathrm{CO}_{2}$ fumigation (Eissenstat et al. 2013; Pritchard et al. 2014). In their case, not only soil fertility, but also other factors such as soil porosity or growth stage of the trees may have affected the responses to $\mathrm{CO}_{2}$ fumigation. 
As been often discussed, root dynamics are affected by various biotic and abiotic factors, although it is not easy to explain the effects quantitatively. Železnik et al. (2016) suggested that growth of fine roots in beech (Fagus sylvatica) stands with different conditions (i.e., old growth forest, managed stands and gaps) was related to forest floor precipitation and soil temperature, whereas fine root mortality was more closely related to maximal evapotranspiration, soil temperature and soil water content. Miyamoto et al. (2016) investigated fine root biomass at tropical heath forests on infertile soils (podzols) and at taller forests on more fertile non-podzolic soils, both of which are located at different altitudes in North Borneo. They found that fine root biomass increased with increasing altitude or decreased with soil fertility, which appears to be related to the extent of soil podzolization. Their linear mixed-effects models indicated that soil $\mathrm{N}$ availability well explained the variation of fine root biomass. Fujii et al. (2016) focused on fine root decomposition, which is also an important process of fine root dynamics. They showed a significantly positive correlation between leaf and root decomposition in a warm temperate forest in Japan, as well as at the global scale, which could be attributed to a wide range of decomposition rates across species and climatic controls.

It is well known that soil acidification induces changes in soil chemical environments, such as low $\mathrm{pH}$, the increase of $\mathrm{Al}^{3+}$ or other toxic metal ions, and the decrease in nutrient availability, and these changes may negatively affect tree growth (Hirano et al. 2007). Moriyama et al. (2016), however, suggested that Al had beneficial effects on root growth of Quercus serrata seedlings. In their experiments, the roots of the seedlings that were treated with $\mathrm{Al}$ also showed increased levels of nitrate reductase, soluble sugars such as glucose and abscisic acid, which could be involved in the increase of root growth. Miyatani et al. (2016) reported fine root traits in seven Chamaecyparis obtusa stands with varied soil acid buffering capacity (soil ABC). They demonstrated that fine roots were more concentrated in the uppermost soil layers in the stands with low soil $\mathrm{ABC}$, where the proportion of thinner fine roots (diam. $<0.5 \mathrm{~mm}$ ) were greater than in high $\mathrm{ABC}$ stands. Their results also indicated that specific root length and respiration of fine roots were correlated with soil $\mathrm{NO}_{3}-\mathrm{N}$ in C. obtusa stands.

Climate warming is also considered to have significant effects on terrestrial ecosystems especially in high latitudes, where warming levels are twice as high as the global average (Cohen et al. 2014). One of the major concerns is the release of greenhouse gasses from the huge soil carbon stock (Zimov et al. 2006), whereas vegetation changes caused by the warming may result in the increase of carbon input into soil by increased plant productivity (MyersSmith et al. 2011). Makoto et al. (2016) investigated soil carbon stock and fine root dynamics in a dry heath alpine tundra on permafrost in Far East Russia, where invasion of dwarf pine (Pinus pumila) has been occurring for the past few decades. Although dwarf pine stands had smaller fine root biomass and greater carbon stock than in the tundra, effects of the dwarf pine invasion were not significant for these below-ground parameters. These results suggested that it would take a long time until the effects of the dwarf pine invasion on below-ground carbon dynamics become evident in alpine tundra of this region. Noguchi et al. (2016) examined fine root biomass in two black spruce (Picea mariana) stands in interior Alaska, which were located on the same north-facing slope, but having differences in depths of permafrost table (shallow vs. deep permafrost plots). They found that both the black spruce trees and understory plants had greater biomass allocation to fine roots in the shallow permafrost plot than in the deep permafrost plot. These results suggest that varied permafrost conditions change above- and below-ground biomass allocation, which, in turn, could affect below-ground carbon dynamics in permafrost forests.

In tropical and subtropical regions, mangrove forests show huge carbon accumulation in the soil, although their distribution is limited to coastal areas (Donato et al. 2011). Since mangrove plants are exposed to adverse conditions such as high salinity, physiological processes of mangrove roots are also an interesting research topic. Srikanth et al. (2016), in their review, comprehensively described morphological and physiological characteristics of mangrove roots. As for salt stress tolerance, they discussed recent progresses on molecular mechanisms controlled under salt stress, which could be a key to understand how mangrove plants have adapted to the coastal environments. Srikanth et al. (2016) also discussed various ecosystem functions of mangrove roots, including flood and sediment control and contribution to biodiversity. Poungparn et al. (2016) reported fine root dynamics in secondary mangrove forests in eastern Thailand, which has three vegetation types from river edge to inland (Avicennia, Rhizophora, and Xylocarpus zones). They showed that fine root biomass in ingrowth cores after 1-year incubation varied greatly among the vegetative zones (290-1170 $\mathrm{g} \mathrm{m}^{-2}$ ), which may be due to varied soil temperature and inundation regimes.

Mycorrhizal symbiosis is beneficial for tree growth since it helps plants to take up nutrients from the soil efficiently. It has also been reported that mycorrhiza alleviated toxic metal and salt stresses and supported water transport (Smith and Read 2008). Nakashima et al. (2016) found that an increased number of ectomycorrhizal root tips improved growth and survival rates of the black pine (Pinus thunbergii) seedlings planted on a coastal area and the effects varied with composition of the ectomycorrhizal fungi. Repo et al. (2016) applied a novel non-destructive 
method based on electrical impedance spectra to examine the degree of freezing injuries of mycorrhizal (Hebeloma sp or Suillus luteus) or non-mycorrhizal roots of Scots pine (Pinus sylvestris) seedlings. Their results suggested that threshold temperature of freezing injury became lower by cold acclimation $\left(-5\right.$ to $-12{ }^{\circ} \mathrm{C}$ vs. -12 to $-18{ }^{\circ} \mathrm{C}$ ), although no difference was found by mycorrhizal treatment. Walker et al. (2016) focused on exoenzyme activity of ectomycorrhiza of hybrid spruce (Picea engelmannii $\times P$. glauca) seedlings planted in forests and clearcut plots. Growth of the spruce seedlings was similar between the plots, although soil nutrient concentration and some of enzymatic activities were lower in the clearcut plots. This may be due to the functional complementarity of the ectomycorrhizal fungal communities, in which, for example, ectomycorrhiza of Thelephora terrestris, a dominant species in clearcut plots, showed very high acid phosphatase activity compared to other fungal species. Leaf $\delta{ }^{15} \mathrm{~N}$ varies with tree species and it often depends on the symbiotic microorganisms in roots (Hobbie and Högberg 2012). Tanaka-Oda et al. (2016) demonstrated that leaf $\delta^{15} \mathrm{~N}$ ranged from -7.2 to $5.0 \%$ in 108 woody species in a Bornean lowland dipterocarp forest. This large variation suggested how diverse $\mathrm{N}$ uptake strategy is (e.g., ecto- or arbuscular-mycorrhizal symbiosis, $\mathrm{N}_{2}$ fixation and ant symbiosis), and concluded that dipterocarp species with ectomycorrhiza showed higher leaf $\delta^{15} \mathrm{~N}$ than other species.

Symbiotic $\mathrm{N}_{2}$ fixation is an important process of $\mathrm{N}$ acquisition for leguminous and actinorhizal tree species, which are known to associate with Rhizobium and Frankia, respectively (Sprent 2005). This process is also an important pathway of $\mathrm{N}$ input into terrestrial ecosystems especially under early successional stage. Tobita et al. (2016), in their review, indicated that $\mathrm{N}_{2}$ fixation rates by Alnus species with Frankia ranged from several to $320 \mathrm{~kg} \mathrm{~N} \mathrm{ha}^{-1}$ year $^{-1}$. Furthermore, they discussed the effects of elevated atmospheric $\mathrm{CO}_{2}$ in relation to other abiotic and biotic factors. They suggested that effects of the elevated $\mathrm{CO}_{2}$ on the $\mathrm{N}_{2}$ fixation were affected by abiotic factors such as soil $\mathrm{N}$ and $\mathrm{P}$ availability, and also by biotic factors such as plant-plant interaction with non- $\mathrm{N}_{2}$-fixing tree species. To study the $\mathrm{N}_{2}$ fixation, especially concerning seedling experiments, reliable techniques of inoculation and plant cultivation are needed. Yamanaka et al. (2016) showed that nodule formation (number) of Frankia-Alnus sieboldiana symbiosis was not significantly different when the inoculum was between 0.1 and $50 \mu \mathrm{L}$ packed cell volume, suggesting a minimum dose of inoculum for constant nodulation. In their experiments, $3.75 \mathrm{mM}$ or lower levels of $\mathrm{N}$ addition did not suppress nodule formation, although $\mathrm{N}_{2}$ fixation activity was lower than control (without $\mathrm{N}$ addition) after a 15 -week treatment.
As mentioned above, a number of studies have focused on fine roots which are a key component of carbon dynamics in terrestrial ecosystems. However, it is not easy to measure growth of fine roots because they turn over rapidly in the soil. Fine root studies in the past decades used various methods such as ingrowth core, minirhizotron, radiocarbon analysis and so on (Lukac 2012; Sah et al. 2013). It was reported that each of these methods has advantages and disadvantages in terms of disturbance effects, cost and labor intensity. In this special issue, three papers discussed methodology for estimating fine root production rates. Do et al. (2016) showed a new approach using ingrowth core and scanner methods combined. They suggested that this combination provided better estimates of fine root production rates in a $Q$. serrata stand by including production of short-living fine roots obtained by the scanner method (two-dimensional image data) in calculations to avoid underestimations that happen by not being able to detect production of such short-living roots with the ingrowth method. Andreasson et al. (2016) compared ingrowth core and ingrowth mesh methods for estimating fine and small diameter roots at Pinus pinaster stands over 3 years. Their results suggested that ingrowth core methods gave more realistic results than the ingrowth meshes, considering the root biomass and morphology obtained by soil cores. Ohashi et al. (2016) also studied the ingrowth mesh (net sheet) method, in which they examined effects of different materials (e.g. polyethylene, stainless steel), aperture size and firmness of the net sheets in Cryptomeria japonica stands in Japan and in a mixed dipterocarp forest in Malaysia. They suggested that flexible nets were better than firm nets to avoid underestimation, whereas the materials and aperture sizes did not affect the estimates of fine root production rates.

As shown here, a variety of tree root studies is presented in this special issue, suggesting that current root studies have targeted diverse physiological and ecological functions of tree roots. It should be noted that new and unique techniques have been applied in these studies. We believe that the papers presented here will greatly improve our knowledge on the diverse functions of tree roots. Furthermore, we hope that this special issue will facilitate further studies on these attractive research topics and contribute to their future progresses. Finally, we appreciate all of the authors for their great contribution to this special issue "Dynamics and physiological processes of tree roots".

Author contribution statement $\mathrm{KN}$ and TK co-edited the special issue and wrote the editorial note.

Acknowledgments We are grateful to Drs. Yasuhiro Hirano and Mizue Ohashi for organizing the "Sixth international symposium on physiological processes in roots of woody plants", which was a great opportunity for sharing novel insights into tree root science and 
stimulated our knowledge for future tree root studies. We thank Japanese Society of Promotion of Science, The Environment Research and Technology Development Fund and many sponsors for their support of our root research. Thanks are also due to Ms. Saki Fujita for her contribution to the editorial works.

\section{References}

Agathokleous E, Watanabe M, Nakaji T, Wang X, Satoh F, Koike T (2016) Impact of elevated $\mathrm{CO}_{2}$ on root traits of a sapling community of three birches and an oak: a free-air- $\mathrm{CO}_{2}$ enrichment (FACE) in northern Japan. Trees. doi:10.1007/ s00468-015-1272-6

Alber A, Ehlting B, Ehlting J, Hawkins BJ, Rennenberg H (2012) Net $\mathrm{NH}_{4}{ }^{+}$and $\mathrm{NO}_{3}{ }^{-}$flux, and expression of $\mathrm{NH}_{4}{ }^{+}$and $\mathrm{NO}_{3}{ }^{-}$ transporters in roots of Picea glauca. Trees 26:1403-1411

Andreasson F, Gonzalez M, Augusto L, Bakker MR (2016) Comparison of ingrowth cores and ingrowth meshes in root studies: 3 years of data on Pinus pinaster and its understory. Trees. doi:10.1007/s00468-015-1256-6

Bloemen J, Teskey RO, McGuire MA, Aubrey DP, Steppe K (2016) Root xylem $\mathrm{CO}_{2}$ flux: an important but unaccounted-for component of root respiration. Trees. doi:10.1007/s00468-015-1185-4

Brassard BW, Chen HYH, Cavard X, Laganière J, Reich PB, Bergeron Y, Pare D, Yuan ZY (2013) Tree species diversity increases fine root productivity through increased soil volume filling. J Ecol 101:210-219

Brunner I, Godbold DL (2007) Tree roots in a changing world. J For Res 12:78-82

Cohen J, Screen JA, Furtado JC, Barlow M, Whittleston D, Coumou D, Francis J, Dethloff K, Entekhabi D, Overland J, Jones J (2014) Recent Arctic amplification and extreme mid-latitude weather. Nat Geosci 7:627-637

Do TV, Sato T, Kozan O (2016) A new approach for estimating fine root production in forests: a combination of ingrowth core and scanner. Trees. doi:10.1007/s00468-015-1195-2

Donato DC, Kauffman JB, Murdiyarso D, Kurnianto S, Stidham M, Kanninen M (2011) Mangroves among the most carbon-rich forests in the tropics. Nat Geosci 4:293-297

Eissenstat DM, McCormack ML, Du Q (2013) Global change and root lifespan. In: Eshel A, Beeckman T (eds) Roots hidden half, 4th edn., Ch. 27, CRC Press, New York, pp 1-13

Fujii S, Makita N, Mori AS, Takeda H (2016) A stronger coordination of litter decomposability between leaves and fine roots for woody species in a warmer region. Trees. doi:10.1007/s00468015-1221-4

Hirano Y, Mizoguchi T, Brunner I (2007) Root parameters of forest trees as sensitive indicators of acidifying pollutants: a review of research of Japanese forest trees. J For Res 12:134-142

Hirano Y, Yamamoto R, Dannoura M, Aono K, Igarashi T, Ishii M, Yamase K, Makita N, Kanazawa Y (2012) Detection frequency of Pinus thunbergii roots by ground-penetrating radar is related to root biomass. Plant Soil 360:363-373

Hobbie EA, Högberg P (2012) Nitrogen isotopes link mycorrhizal fungi and plants to nitrogen dynamics. New Phytol 196:367-382

Laur J, Hacke UG (2013) Transpirational demand affects aquaporin expression in poplar roots. J Exp Bot 64:2283-2293

Lukac M (2012) Fine root turnover. In: Mancuso S (ed) Measuring roots. Springer, Berlin, pp 363-373

Makoto K, Bryanin SV, Lisovsky VV, Kushida K, Wada N (2016) Dwarf pine invasion in an alpine tundra of discontinuous permafrost area: effects on fine root and soil carbon dynamics. Trees. doi:10.1007/s00468-015-1192-5
McLean EH, Ludwig M, Grierson PF (2011) Root hydraulic conductance and aquaporin abundance respond rapidly to partial root-zone drying events in a riparian Melaleuca species. New Phytol 192:664-675

Meier IC, Avis PG, Phillips RP (2013) Fungal communities influence root exudation rates in pine seedlings. FEMS Microbiol Ecol 83:585-595

Miyamoto K, Wagai R, Aiba S, Nilus R (2016) Variation in the aboveground stand structure and fine-root biomass of Bornean heath (kerangas) forests in relation to altitude and soil nitrogen availability. Trees. doi:10.1007/s00468-015-1210-7

Miyatani K, Mizusawa Y, Okada K, Tanikawa T, Makita N, Hirano Y (2016) Fine root traits in Chamaecyparis obtusa forest soils with different acid buffering capacities. Trees. doi:10.1007/s00468015-1291-3

Moriyama U, Tomioka R, Kojima M, Sakakibara H, Takenaka C (2016) Aluminum effect on starch, soluble sugar, and phytohormone in roots of Quercus serrata Thunb. seedlings. Trees. doi:10.1007/s00468-015-1252-x

Myers-Smith IH, Forbes BC, Wilmking M, Hallinger M, Lantz T, Blok D, Tape KD, Macias-Fauria M, Sass-Klaassen U, Levesque E, Boudreau S, Ropars P, Hermanutz L, Trant A, Collier LS, Weijers S, Rozema J, Rayback SA, Schmidt NM, SchaepmanStrub G, Wipf S, Rixen C, Menard CB, Venn S, Goetz S, Andreu-Hayles L, Elmendorf S, Ravolainen V, Welker J, Grogan P, Epstein HE, Hik DS (2011) Shrub expansion in tundra ecosystems: dynamics, impacts and research priorities. Environ Res Lett 6:045509

Nakaji T, Noguchi K, Oguma H (2008) Classification of rhizosphere components using visible-near infrared spectral images. Plant Soil 310:245-261

Nakashima H, Eguchi N, Uesugi T, Yamashita N, Matsuda Y (2016) Effect of ectomycorrhizal composition on survival and growth of Pinus thunbergii seedlings varying in resistance to the pine wilt nematode. Trees. doi:10.1007/s00468-015-1217-0

Noguchi K, Matsuura Y, Sparrow SD, Hinzman LD (2016) Fine root biomass in two black spruce stands in interior Alaska: effects of different permafrost conditions. Trees. doi:10.1007/s00468-0151226-Z

Ohashi M, Nakano A, Hirano Y, Noguchi K, Ikeno H, Fukae R, Yamase K, Makita N, Finér L (2016) Applicability of the net sheet method for estimating fine root production in forest ecosystems. Trees. doi:10.1007/s00468-015-1308-y

Poungparn S, Charoenphonphakdi T, Sangtiean T, Patanaponpaiboon $P$ (2016) Fine root production in three zones of secondary mangrove forest in eastern Thailand. Trees. doi:10.1007/s00468015-1220-5

Pritchard SG, Taylor BN, Cooper ER, Beidler KV, Strand AE, McCormack ML, Zhang S (2014) Long-term dynamics of mycorrhizal root tips in a loblolly pine forest grown with free-air $\mathrm{CO}_{2}$ enrichment and soil $\mathrm{N}$ fertilization for 6 years. Global Change Biol 20:1313-1326

Repo T, Korhonen A, Lehto T, Silvennoinen R (2016) Assessment of frost damage in mycorrhizal and non-mycorrhizal roots of Scots pine seedlings using classification analysis of their electrical impedance spectra. Trees. doi:10.1007/s00468-015-1171-x

Sah SP, Bryant CL, Leppälammi-Kujansuu L, Lõhmus K, Ostonen I, Helmisaari H-S (2013) Variation of carbon age of fine roots in boreal forests determined from ${ }^{14} \mathrm{C}$ measurements. Plant Soil 363:77-86

Smith SE, Read D (2008) Mycorrhizal symbiosis, 3rd edn. Aademic Press, Singapore

Sprent JI (2005) Biological nitrogen fixation associated with angiosperms in terrestrial ecosystems. In: BassiriRad H (ed) Nutrient acquisition by plants, an ecological perspective. Springer, Heidelberg, pp 89-116 
Srikanth S, Lum SKY, Chen Z (2016) Mangrove root: adaptations and ecological importance. Trees. doi:10.1007/s00468-015-1233-0

Tanaka-Oda A, Kenzo T, Inoue Y, Yano M, Koba K, Ichie T (2016) Variation in leaf and soil $\delta^{15} \mathrm{~N}$ in diverse tree species in a lowland dipterocarp rainforest. Trees, Malaysia. doi:10.1007/ s00468-015-1298-9

Tobita H, Yazaki K, Harayama H, Kitao M (2016) Responses of symbiotic $\mathrm{N}_{2}$ fixation in Alnus species to the projected elevated $\mathrm{CO}_{2}$ environment. Trees. doi:10.1007/s00468-015-1297-x

Walker JKM, Ward V, Jones MD (2016) Ectomycorrhizal fungal exoenzyme activity differs on spruce seedlings planted in forests versus clearcuts. Trees. doi:10.1007/s00468-015-1239-7

Wang X, Fujita S, Nakaji T, Watanabe M, Satoh F, Koike T (2016) Fine root turnover of Japanese white birch (Betula platyphylla var. japonica) grown under elevated $\mathrm{CO}_{2}$ in northern Japan. Trees. doi:10.1007/s00468-015-1282-4

Yamanaka T, Okabe H, Kawai S (2016) Growth and nodulation in Alnus sieboldiana in response to Frankia inoculation and nitrogen treatments. Trees. doi:10.1007/s00468-015-1246-8

Železnik P, Vilhar U, Starr M, de Groot M, Kraigher H (2016) Fine root dynamics in Slovenian beech forests in relation to soil temperature and water availability. Trees. doi:10.1007/s00468015-1218-Z

Zimov SA, Schuur EAG, Chapin FS III (2006) Permafrost and the global carbon budget. Science 312:1612-1613 